\title{
Research on Children's Medical Products Design Based on Gamification*
}

\author{
Xinhui Hong \\ Fuzhou University \\ Xiamen, China 361000
}

\author{
Xiantong Zhan \\ Fuzhou University \\ Xiamen, China 361000
}

\begin{abstract}
Objective: To analyze the possibility of gamification in children's medical product design. Method: the author analyzes the status and development of children's medical products, interprets the connotation and characteristics of gamification, analyzes the possibility of applying gamification in children's medical product design combining with case analysis, and discusses the feasibility and necessity of gamification of children's medical product design. Conclusion: The gamification design and children's medical product design have consistent goal, similar process, and corresponding concept. The gamification of children's medical product design can effectively improve the participation, compliance, and pleasure of children's diagnosis and treatment, which is an important means to drive the innovation of children's medical product design.
\end{abstract}

Keywords-gamification; user experience; children medical treatment; medical equipment

\section{INTRODUCTION}

People will inevitably "make contact with" various kinds of medical equipment in life. In the early years, most of the medical equipment was function-oriented, with low affinity and poor experience. With the advancement of society and economic development, the people-oriented design concept has been deeply rooted in people's minds. How to create a good user experience for medical products, especially children's medical products, has gradually attracted the attention of all sectors of society, which requires that children's medical product design need to integrate more excellent experience. The "In-hospital Children's Gaming Services Project" introduced to China's Right To Play in 2016 was a representative. It incorporated the concept of "gambling of medicine" into hospital services to eliminate children's fears and anxiety to hospitals and improve children's adaptability to hospital and cooperation to the treatment, as well as foster children's positive attitude. Therefore, introducing the gamification idea into the design of children's medical products to improve the user experience in children's medical treatment has become one of the important trends in the design of children's medical products.

*Fund Project: Fujian Provincial Social Science Planning Project (FJ2016B215); Fujian Provincial Education Science "Twelfth Five-Year Plan" Project (FJJKCG15-101); Fujian Innovation and Entrepreneurship Education Reform Pilot Project

\section{The CURRENT SitUATION AND DEVELOPMENT OF CHILDREN'S MEDICAL PRODUCTS}

\section{A. Status Quo of Children's Medical Products}

At present, there is a large gap in the market for dedicated children's medical products in China, and children are often referred to as "little adults." The downsizing of adult medical devices is defined as children's medical products, and actually only a small number of medical products specifically for children's $R \& D$ are designed. Taking the respiratory mask as an example, the difference between most existing respiratory masks for children and that for adult is only the difference in the man-machine size, but adults who have established medical cognition are familiar with the usage of respiratory masks while children are full of unknown fears for the masks covering the mouth and nose. Therefore, the reduced version of the respiratory mask can meet the physiological needs of children's disease treatment, but it cannot alleviate children's anxiety, and fails to meet the children's psychological needs for respiratory masks, see "Fig. 1".

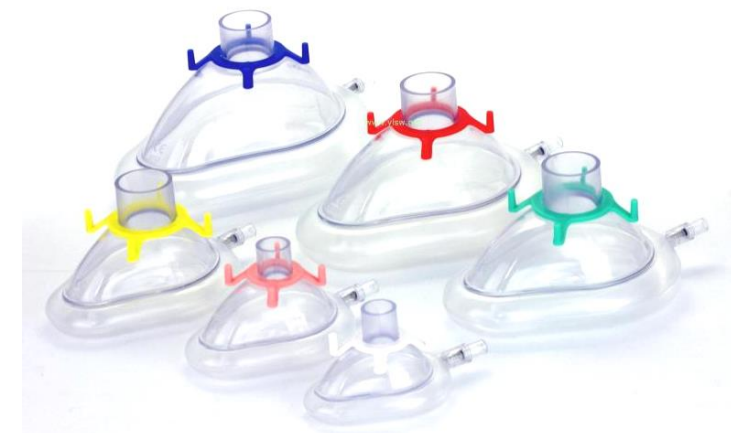

Fig. 1. Respiratory mask for children and adults.

Functionalism, on the other hand, occupies a dominant position in the design of children's medical products. The products are rich in technical expertise, but the feelings of children who are ill during use are often overlooked, which leads to crying and resistance in the process of children's diagnosis and treatment. The phenomenon of rejecting cooperation is serious. Nowadays, with the development of children's medical systems, this situation needs to be changed urgently, and design is intervened in the medical system as a new perspective and tool [1]. 


\section{B. Development of Children's Medical Products}

Children generally have anxiety, fear, resistance, and dependence psychologically in the diagnosis and treatment, which are reflected as crying, rejecting to accept and cooperate with treatment in the behavior, and even have transient behavioral degeneration. Children's psychological and behavioral specialties make it impossible to treat children as "small adults"' in medical products design. With the advent of the experience-centered design era, children's medical product design should think from the perspective of children. It should not only examine its professionalism, but also meet the psychological needs of children.

Therefore, children's medical products must first help children eliminate the fear of diagnosis and treatment, make children willing to try and willing to cooperate after the trial, and attract children's attention in a more relaxed and interactive manner of diagnosis and treatment, so that they can better participate in the process of diagnosis and treatment and improve their compliance with treatment. In addition, children's medical products should also improve children's interest in diagnosis and treatment, enhance the interaction of diagnosis and treatment to help children face the diagnosis and treatment with a positive attitude, and ultimately improve the treatment effect and efficiency. For example, Pain Squad, an app that helps children with cancer to collect physical and mental health more easily, has been recruited into the police as an "inspector" for the disease in the game. They want to complete the task of hunting down "pain", and report physical health twice a day. There is a promotion rule in the game. If the children complete the pain report for three consecutive days, they will receive the badge reward and be promoted from a rookie to a sergeant until they are promoted step by step to the chief executive. Pain Squad's gamificationsolution has been a great success, and the final health report of children suffering from cancer has reached $90 \%$.

\section{GAMIFICATION}

\section{A. The Definition of Gamification}

In 1980, Professor Chad Battelle of the University of Essex put forward "gamification": Turning things or jobs that are not games into games. In 2002, Nick Pelling, a British consultant, used the word "Gamification" for the first time to describe the behavior of "accelerating user interface design by using games to make electronic transactions fast and entertaining." [2]. Sebastian Deterding and Rilla Khaled have scientifically defined gamification and believed that gamification is the use of game design elements in non-game contexts [3]. Kai Huotari and Juho Hamari believe that gamification is a service process that supports the user's overall value creation and improves the usability of the game-like experience [4]. In 2014, Kevin Weibach and Dan Hunter proposed in the book "gamification of Thinking" that gamification refers to the use of game elements and game design techniques in non-game situations [5]. The author believes that gamification is the use of gamification elements and gamification mechanisms to solve real problems, so that the original ordinary experience becomes as lively and interesting as the game. Under the guidance of the gamification design strategy, the elements and mechanisms of gamification are flexibly used to carry out planned and directional designs, ultimately bringing interesting experiences to the users and driving the participants to generate corresponding behavior changes.

\section{B. Gamification Features}

First is interestingness. Interestingness is the soul of the product, and it has the power to give the product emotions and life. The gamification also has the "magic" that transform ordinary things to magical things. The daily work or learning task is transformed into the challenge with storyline and full of interestingness through the game design, which can not only arouse the emotional resonance of users, but also create a happy and enjoyable experience for users. For example, the Will Carey inflatable fish tank for training vital capacity is a fish tank connecting to an air-blowing hole, and the children will improve their lung capacity by breathing to the fish tank. The treatment task is converted into an interesting game, as shown in "Fig. 2".

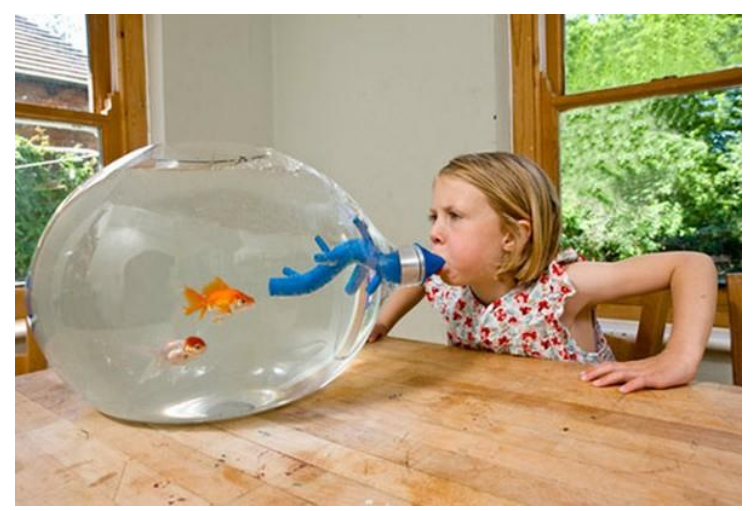

Fig. 2. Will Carey inflatable fish tank.

Second is high efficiency. The gamification system will issue clear tasks to the user, inform the user of the rewards for completing the task, and guide the user to complete the task step by step. It gives people a specific goal to ensure that they can complete and expect something so as to make gamification activities or learning activities more efficient. Users don't have any questions about what to do and how to do it. This efficient activity is exactly what the user expects. For example, mental health counseling software SuperBetter will disperse the user's rehabilitation goals into a number of small tasks and track the completion situation of the task, to provide users with scientific guidance video, allowing users to better understand the rehabilitation of mental illness tips, and guide the user to achieve the goal step by step. In such gamification system, restoring mental health becomes more efficient and easier, as shown in "Fig. 3". 


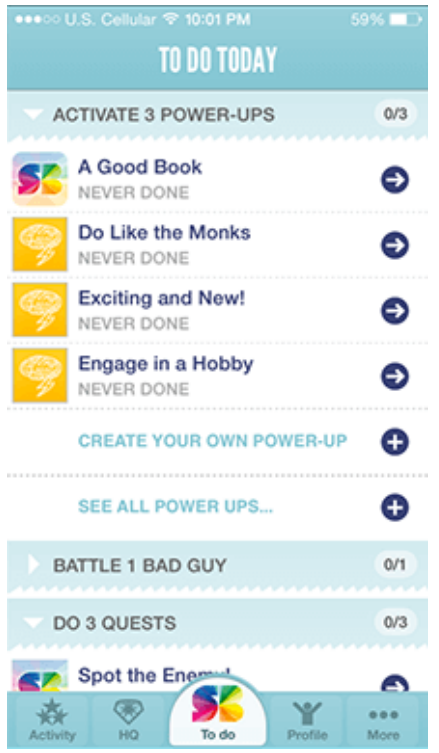

Fig. 3. SuperBetter software interface.

Third is immediacy. In the gamification system, users can see the results of their own efforts immediately after completing the task. Even if it is a failure, users can easily know where the mistakes are and correct them. At the same time, in the visual feedback, the user sees that his ability has been continuously improved over time, and his actions have become more and more important to the surrounding world, which gives the user a real sense of accomplishment. For example, diabetes behavior changing game Mysugar can provide instant feedback for patients with diabetes, and users complete tasks to get points to domesticate "diabetic pets". In the process of users domesticating pets, their condition can be monitored continuously, and it instantly provides different tasks for the users with different conditions, so that users gradually change the behavior in the process of completing the task and achieve therapeutic effects, see "Fig. 4".

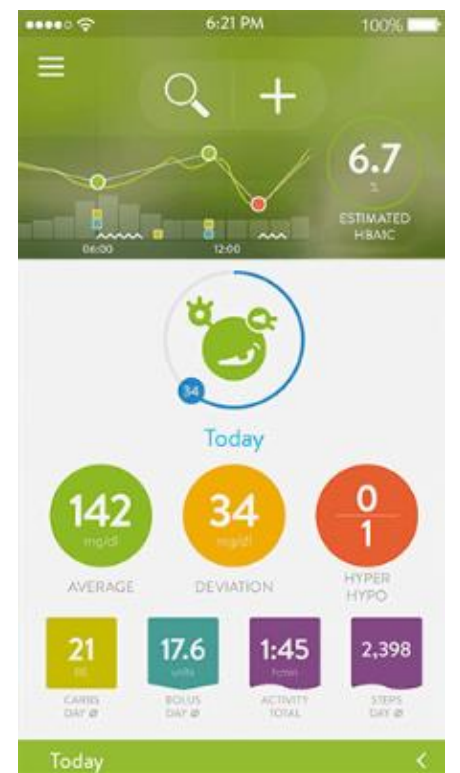

Fig. 4. Mysugar software interface.

\section{APPLICATION OF GAMIFICATION IN CHILDREN'S MEDICAL PRODUCT DESIGN}

The design concept of children's medical products has evolved to a people-oriented stage. The user experience has received more and more attention in the design of children's medical products in foreign countries. However, there is still a gap in the design of domestic children's medical products compared with developed countries. The problem of poor experience of children's medical treatment is outstanding. We all know that games are "happy passwords" for children's growth. The combination of games with children's health management, disease prevention, and the establishment of medical awareness have provided a new possibility for improving children's medical experience.

\section{A. The Success of Gamification in Children's Medical Product Design}

The future medical scientist Hitara Maeske believes that gamification is one of the trends of future medical health [6]. Indeed, gamification is affecting the children's medical industry. More and more gamified children's medical products are beginning to appear, such as Kaspar, which helps children with autism, and Wellapets, which helps children control asthma. Next, the author uses Kitten Scanner and Wizdy Pets as examples to analyze the possibility of the gamification experience in children's medical product design.

Kitten Scanner is a gamified pediatric MRI scanner designed by Philips. It combines gamification and MRI scanning technology to help children overcome the fear of MRI scanning. Children are very repulsive to MRI scans. Cold machines and narrow spaces are full of unknown fears for them. The traditional approach is to first inject sedatives to children, and wait for the children to become unconscious before making MRI scans. The sense of fear will still have a lasting impact on children's hearts. Kitten Scanner uses a miniature MRI demo model to allow children to choose elephants, crocodiles, robots, or chicks on a toy scanner and push them into the Kitten Scanner. The screen beside will show simulation animations for children, demonstrating the working principle of the scanner in a lively and fun way for children. During the simulation operation, children establish medical knowledge about MRI scanning and eliminate the fear of the huge MRI scanner, so that they began to be willing to accept the scan, and dare to complete the inspection with a large scanner alone. After using Kitten Scanne's to gamify Children's MRI scanner, the number of children who originally need anesthetic injections is greatly reduced, and the degree of satisfaction of children is greatly improved, as shown in "Fig. 5". 


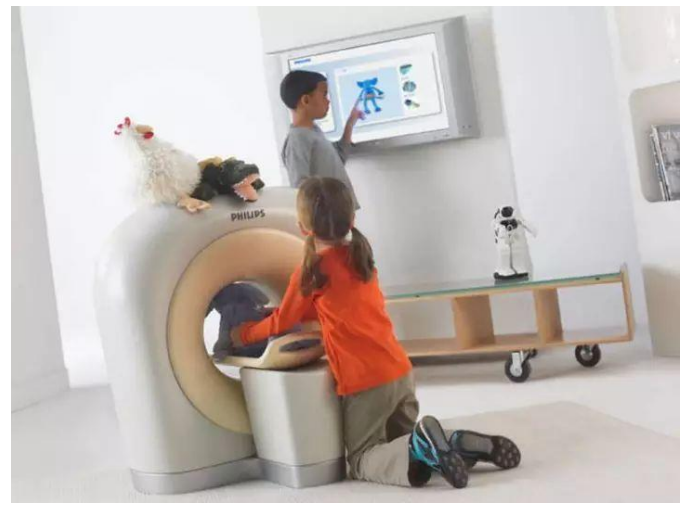

Fig. 5. Kitten Scanner nuclear magnetic resonance scanner for children.

Wizdy Pets is a gamified application that helps children control asthma through pet fostering. Children adopt exclusive virtual pets, select interesting tasks in the task list, and get points after the completion to buy toys and props for pets. They can play with pets, and take care of the asthma of pets, etc. The game doesn't have fixed program, so that children can explore it by themselves step by step and learn happily about asthma during the pet raising process. Wizdy Pets has also built a virtual community for children. Children can play with different friends and work together to defeat monsters, which can cultivate their team spirit. Social networking in the game also promotes children's communication. Wizdy Pets helps doctors build bridges with their children through game language they can understand, talk about diseases with children in a fun way, talk about health in an easier way, and teach them how to stay healthy, see "Fig. 6".

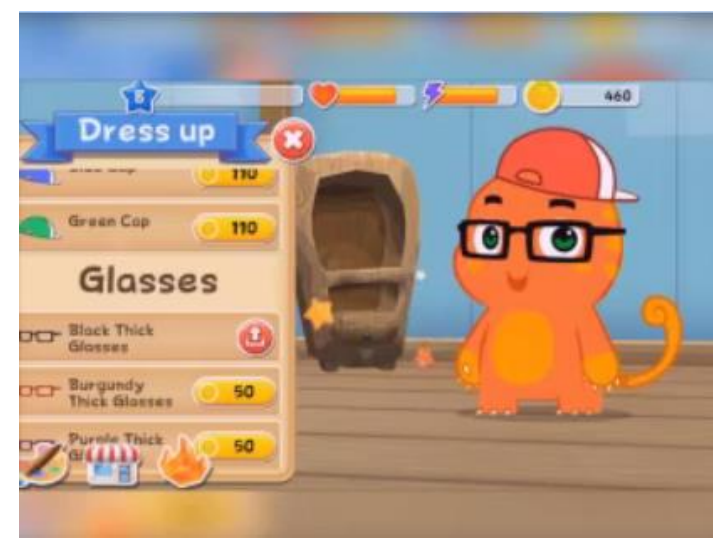

Fig. 6. Wizdy Pets interface.

Kitten Scanner and Wizdy Pets have eased the anxiety of children's medical treatment through gamification, created a relaxed atmosphere for diagnosis and treatment, and improved the experience of children's medical treatment. From this we also see the potential of gamification in children's medical product design.

\section{B. Feasibility of Gamification in Children's Medical Product Design}

First of all, the goal of gamification design and children's medical product design is consistent, and they are all committed to improving the experience of children's medical treatment. Good children's medical products are a combination of excellent functions and experiences. The functions of today's children's medical products have generally been guaranteed, so users have begun to pursue more "non-material" spirits and experiences, and the focus on children's medical products is gradually transferred to the children's psychology and medical experience. Gamification, based on the grasp of user motivation and demand, use gamification thinking and mechanism as design tools to induce and inspire children's curiosity, and satisfy people's pursuit of positive emotional experience [7-8]. There are numerous cases that cross-border fusion of gamification design and children's medical product design enhance the experience. For example, game company Nintendo applies the classic cartoon image Pokemon to X-ray machines, and the attractive $\mathrm{X}$-ray machine makes children no longer hide under the bed to escape from check.

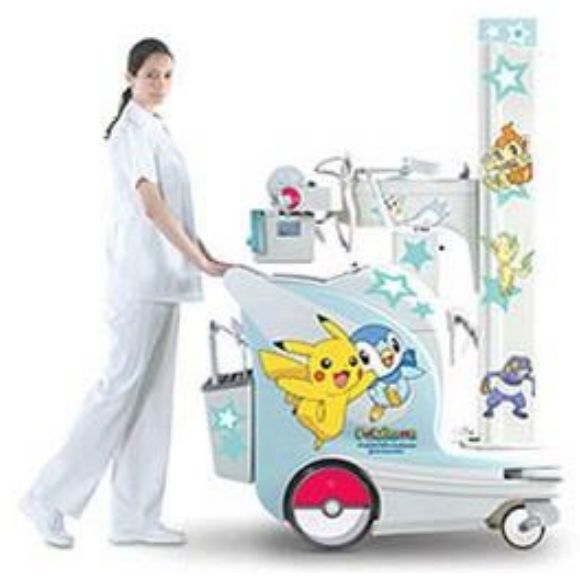

Fig. 7. Nintendo cartoon theme $\mathrm{X}$ ray machine.

Second, the process of gamification design and children's medical product design has similarities. As shown in "Fig. 8", both the gamification design and children's medical product design should be people-oriented. Therefore, the starting point of the design is to deeply understand the user, explore the user's needs and design opportunities, and build a game design program model or design the concept of children's medical products based on this. Then they define children's medical products, make hardware and software design, interactive design, and UI design, etc. Finally, the feasibility of the product is tested through the establishment of a prototype. There are many similarities between the gamification design and the children's medical product design process, but it needs further exploration to integrate the concept of gamification in the design of children's medical products. 


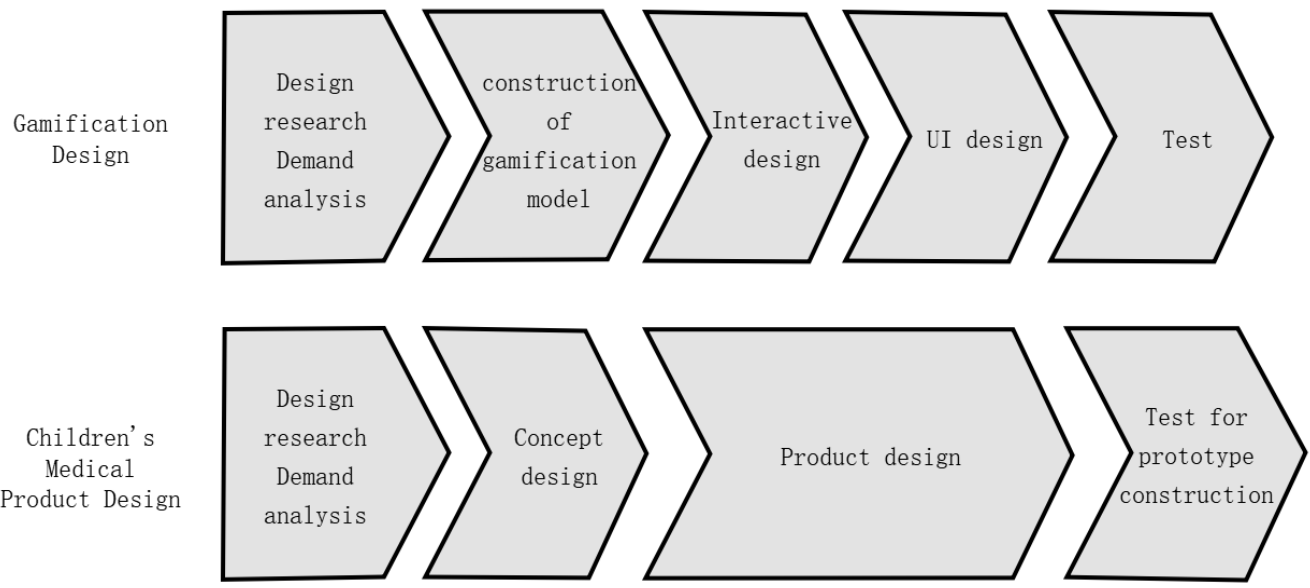

Fig. 8. Gamification design and children's medical product design process.

Third, the concept of gamification design and children's medical product design is consistent. Children are eager to have a pleasant and relaxed manner of diagnosis and it is because of this that gamification is used as a new method to help children reduce the pain of medical treatment and improve the treatment experience. On the other hand, gamification has gradually attracted the attention of related academic circles since 2010 [9]. The existing gamification ideas mostly come from the field of games and there are still a lot of gaps in the theoretical research of gambling design. The attempt of gamification design in children's medical care not only expands the application scope of gamification, but also makes the theory of gamification continue to be enriched in practice. Cross-border integration of gamification design and children's medical product design will also maintain interaction and common development.

\section{The Necessity of Gamification in Children's Medical Product Design}

Compared with the traditional children's medical product design, gamification brings about three aspects of improvement in children's medical product design: participation, compliance and pleasure. In the traditional medical model, most children are not fully involved but choose to avoid. Forced treatment not only reduces the efficiency of pediatric treatment, but also results in poor treatment. The excellent gamification can design more interesting treatment methods for children, so that children patients are more willing to try and actively participate in the treatment process. Applying Gamification to the design of children's medical products can create an immersive experience for children, effectively improve children's compliance with medical treatment and make children fully participate in treatment. In addition, challenge mechanisms, competition mechanisms, and cooperation mechanisms of gamification can create a pleasant experience for children patients and help children patients to receive treatment more easily.

The user value of gamification of children's medical product design is obvious, and gamification is also profoundly affecting the children's medical product industry.
On the one hand, gamification can improve the user experience of children's medical products. In the new era of "experience economy", experience values gradually began to occupy the core position of people's daily decision-making, and high-quality user experience has become the biggest advantage of enterprise competition [10]. Gamification can transform children's medical treatment and improve children's medical experience. PediSedate, a children's anesthesia machine shown in "Fig. 9", turns tooth extraction into a musical journey in order to reduce the resistance and fear of dental treatment for children. PediSedate's shape is like a headset with a mask added to the nose and mouth. The built-in music player plays automatically when the child wears it. When playing music, the mask releases the anesthetic, so that the child is slowly anesthetized in the process of enjoying the wonderful melody of the music. And teeth are already removed when they are awake. This minor change makes children's medical products present a completely different experience. On the other hand, gamification can drive the innovation of children's medical product design, and gamification design has gradually formed a large number of creative thinking. Gamification will have more creative applications in children's medical science education, diagnosis and treatment, and rehabilitation. There will be more and more successful cases that gamification drive the innovation of children medical product design.

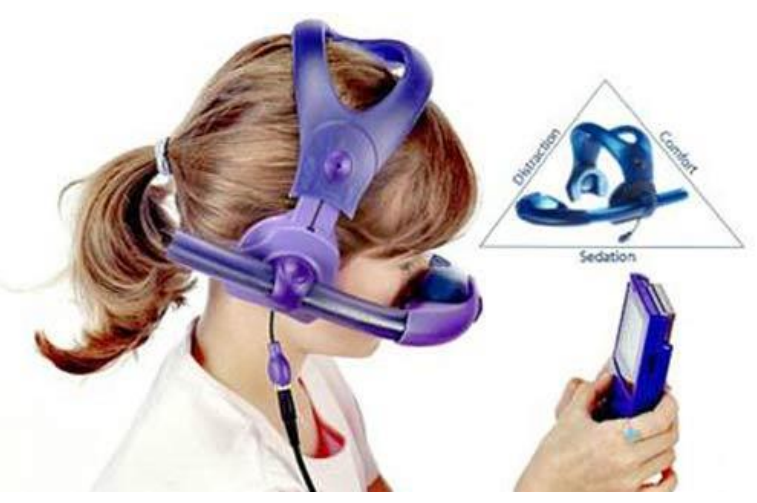

Fig. 9. PediSedate children's anesthesia game machine. 


\section{CONCLUSION}

In the context of the current poor experience of children's medical treatment, it is feasible and necessary to integrate gamification into the design of existing children's medical products to improve the experience of children's medical treatment. Gamification, whether in the prevention stage, the treatment stage or the rehabilitation stage of the children's medical treatment, can optimize the experience, add enjoyment of medical treatment and improve the compliance, effectiveness and enthusiasm of children's medical treatment, which has very important significance for children's health.

\section{REFERENCES}

[1] Wen Jing-zhu,Zhang Ling-hao. Application of Empathic Design in Children Dental Products Experience Design[J]. Packaging Engineering,2015,(20):70-73. 文菁竹,张凌浩. 移情设计在儿童牙 科产品体验设计中的运用[J]. 包装工程,2015(20):70-73.

[2] Brian Burke. Gamify[M]. Liu Teng. Wuhan:Huazhong University of Science and Technology Press,2017. 布莱恩. 伯克. 游戏化设计[M]. 刘腾译. 武汉:华中科技大学出版社, 2017.

[3] Deterding S, Khaled R, Nacke L, et al. Gamification: Toward a definition[C]// CHI 2011 Gamification Workshop Proceedings. 2011:12-15.

[4] Kai H, Hamari J. Defining gamification: a service marketing perspective[C]// Proceeding of the, International Academic Mindtrek Conference. ACM, 2012:17-22.

[5] Kevin Werbach,Dan Hunter. For the win: How Game Thinking Can Revolutionize Your Business[M]. Zhou Kui,Wang Xiaodang. Hangzhou:Zhejiang People's Publishing House,2014. 凯文·韦巴赫, 丹. 亨特. 游戏化思维[M]. 周逵, 王晓丹译. 杭州: 浙江人民出版社, 2014.

[6] Bertalan Meskó. The Guide to the Future of Medicine: Technology and the Human Touch[M]. Big data digest translation group. Beijing:China Renmin University Press,2016. 赫塔拉. 麦斯可. 颠覆 性医疗革命:未来科技与医疗的无缝对接 [M]. 大数据文摘翻译组 译. 北京:中国人民大学出版社, 2016 .

[7] Chen Cheng. Design Mobile Application Products with Gamification Thinking[J]. Modern Decoration: Theory,2015,(1):14-15. 陈骋. 用 游戏化思维设计移动应用产品[J]. 现代装饰:理论, 2015(1):14-15.

[8] Wang Teng,Li Cheng-min,Wu Jian-feng,et al. Design and Application of Gamification Theory in Sports APP $[\mathrm{J}]$. Packaging Engineering,2017,(22):48-52. 王腾, 李成敏, 吴剑锋等. 游戏化理论 在运动类 APP 中的设计应用方法研究[J]. 包装工程,2017(22):4852.

[9] Wu Xiao-yu,Xin Xiang-yang. Gamification Design Application to Persuade User Behavior Change[J]. Packaging Engineering,2017,(20):194-198. 武笑宇, 辛向阳. 劝导用户行为改 变的游戏化设计应用[J]. 包装工程,2017(20):194-198.

[10] Jane McGonigal. Reality Is Broken: Why Games Make Us Better and How They Can Change the World[M]. Lv Jia. Beijing:Beijing United Publishing Company,2012. 简. 麦戈尼格尔. 游戏改变世界[M]. 闾 佳译. 杭州:浙江人民出版社, 2012. 